\title{
LOS BALDÍOS Y EL PROBLEMA AGRARIO EN LA COSTA CARIBE DE COLOMBIA (1830-1900)
}

\author{
Hermes Tovar Pinzón \\ Director Centro de Investigaciones de Historia \\ Colonial, Instituto Colombiano de Cultura Hispánica, \\ Bogotá
}

\section{INTRODUCCIÓN}

La ocupación de los espacios baldíos de la República de Colombia durante el siglo XLX no fue un fenómeno circunscrito a la llamada región Antioqueña. ${ }^{1}$ Prácticamente todo el territorio nacional se vio congestionado con demandas de titulación y apropiación de terrenos y globos baldíos, tanto por parte de grandes empresarios, como de pequeños y modestos colonos. ${ }^{2}$ El significado social y económico que el desplazamiento de gentes tuvo en el conjunto de cada región, otorgó a la cuestión agraria rasgos diferenciados en la incorporación de nuevos baldíos y en las disputas por la titulación de las tierras. Del mismo modo, la ubicación geográfica y la fertilidad de los suelos contribuyeron a que la frontera fuera variada e indistinta, así como la presencia o la ausencia de comunidades humanas hizo de la frontera un lugar vacío o semi-vacío. Es decir, que los derechos adquiridos o pretendidos por los pobladores contribuyeron a definir el carácter de las colonizaciones y de las regiones. ${ }^{3}$ Colombia, Medellín, Diciembre de 1984, No. 18, Pág.3H3.

2 Catherine Le Grand, Colonización y protesta campesina en Colombia, 1830-1950, Universidad Nacional de Colombia, Bogotá 1988; Hermes Tovar Pinzón, Que nos rengan en cuenta: colonos, empresarios y aldeas (1800-1900), Bogotá, 1995.

3 Marco Palacios, El café en Colombia 1850-1970, una historia económica, social y política, Ancora editores, Bogotá, 1983, Págs.123-337. 
Hubo regiones en donde la tierra baldía lo era sólo por disposición jurídica, pues por razones de posesión, pertenecía a indígenas, a colonos perdidos, a trabajadores inéditos, a terrajeros marginados, a arrendatarios envejecidos o a modestos y grandes tenedores. Ellos la defendieron como suya cuando aparecieron los edictos públicos, sobre puertas y paredes de alcaldías y juzgados, para anunciar las denuncias de quienes pretendían ser sus nuevos propietarios. Aquellos habitantes desconocidos y sin registro en las notarías públicas, que habían vivido confundidos con la naturaleza, sobreviviendo entre la selva, el bosque y la montaña, se opusieron a quienes llegaron con agrimensores para delimitar terrenos bajo la protección de las autoridades locales. Acompañados de un título, un decreto o un reconocimiento de servicios prestados, en una o varias de las tantas guerras civiles que fundamentaron la grandeza de Colombia, estos personajes pretendieron desplazar a quienes vivían entre los baldíos. Tales territorios fueron escenarios de conflictos entre poseedores históricos y quienes llegaban amparados por las nuevas leyes que entregaban tierras y bosques nacionales. Pero el conflicto y la violencia no signaron todo el proceso de ocupación de las tierras públicas. Hubo fronteras vacías en donde se pudo reubicar a decenas de familias humildes y satisfacer la avaricia o el interés económico de grandes señores. Si bien la colonización del siglo XIX significó en muchas regiones la consolidación de grandes latifundios, en otras representó un camino hacia el bienestar y el mejoramiento de las condiciones de vida de miles de familias desposeídas.

Cuando los legisladores colombianos decidieron entregar a los colonos tierras para que fundaran riqueza e independencia como basamentos de una democracia de hombres libres, lo que quisieron fue seguir el modelo Americano. Indudablemente que ellos se equivocaron, pues la expansión de los ideales americanos hacia el Oeste se hizo expulsando brutalmente a los indios y entregando sus tierras a todos los que empujaban hacia el Pacífico. El ejército Americano llegaba a respaldar las invasiones de los blancos y, tras una batalla sangrienta, los indios eran forzados a aceptar y firmar unos nuevos límites de sus territorios. Como los colonos seguían avanzando ajenos a todo tratado, el ejército de la Unión volvía otra vez a correr la frontera humedecida con la sangre de Iraqueses, Apaches, Creeks, Comanches, Cherokees, Shoshones y Navajos. ${ }^{4}$

En Colombia, no fue posible colocar a los desposeídos en las tierras que iban invadiendo, pues los grandes latifundistas defendieron en algunas regiones el derecho a sus propiedades y, más bien, arropados por la ley, se lanzaron a apoderarse de nuevas extensiones de tierra. Los que mejor aprovecharon estos ideales democratizantes de la clase política colombiana fueron los antioqueños, que habían encontrado una fron-

4 Sanford Wexler, Westward expansion: An eyewitness History, Facts on File, New York - Oxford, 1991; Raymond J. DeMallie, "These Have No Ears: Narrative and the Etlinohistorical Method", en: Etnohistory, 40:4, Fall, 1993, Pág. 515-537; Frederick Merk,, History of the Westward Movement, New York, Alfred A. Knop, 1978. 
tera abierta al sur y llevaron hasta ella un modelo de entrega de tierras que integraba fundación de pueblos, apertura de caminos, ampliación de mercados y valorización de suelos. Este proyecto no fue practicado en ninguna otra región de Colombia. Mas bien el modelo individual de apropiación de grandes o pequeñas extensiones condicionó el proceso social de transformación de las tierras públicas en bienes privados. Por tanto la colonización antioqueña no solo creó una sociedad de pequeños tenedores sino que superó el conflicto, que fue más intenso en aquellas regiones en donde el modelo de colonización integró despojo, aislamiento y amañamiento con los poderes locales para atentar contra los ocupantes previos de los baldíos.

El hecho de que en Antioquia hubiera predominado el poblamiento, con un proceso de distribución de tierras, no significa que su territorio no hubiera ofrecido otras formas de colonización, tal como lo atestiguan los movimientos de gentes hacia el nordeste y noroeste en donde los intereses de los hacendados y de los ocupantes históricos de los baldíos entraron en disputa.

En realidad las diversas regiones de Colombia vivieron, entre 1800 y 1900, una inquietante actividad migratoria que se fue acentuando a lo largo de la centuria. En el Cauca las gentes se movían hacia Barbacoas, hacia el norte del Valle y hacia las montañas de Nariño y Caquetá. Un hervidero humano avivaba los caminos de Colombia, atraído por ofertas imprecisas, por mercados desconocidos o por una difusa ilusión de riqueza y bienestar. Los bosques de tagua, de añil, de quina y de caucho se vieron súbitamente invadidos por humildes trabajadores que, atados por la novedad del capital, descuajaban brutalmente la montaña alterando cadenas ecológicas, abriéndole huellas a la erosión y cambiando las formas del paisaje. En la vertiente occidental de la cordillera central las gentes marcharon buscando tierras para la ganadería, mientras que en la costa Caribe de Colombia los colonos sembraban café, cacao y caña de azúcar y otros plantaban plátano, maíz, yuca, arroz y pastos artificiales. ${ }^{5}$

El significado específico de estos movimientos humanos en cada región, y su peso relativo frente al problema agrario del siglo XIX en Colombia, apenas se empiezan a estudiar. El fenómeno más conocido es el de los antioqueños que lograron cohesionar su región y un proyecto de desarrollo empresarial desde fines del siglo XVIII y comienzos del siglo XIX. No obstante en este esfuerzo poblador, que desbordó sus propios límites, los antioqueños no lograron extrapolar su espíritu colonizador al conjunto de la nación. Su fracaso es comprensible por la presencia de otros poderes regionales, cuyos proyectos de colonización no se hicieron básicamente sobre tierras nuevas, para fundar poblados, sino sobre tierras que ya habían sido incorporadas por trabajadores alejados de los centros urbanos. Era muy difícil vender a las regiones un

5 Archivo General de la Nación (Bogotá), Baldíos, 15 ff. 67r. y 342r. 
ideal que había sido propio de los antioqueños. Incluso la dilución de su colonización en el norte del Valle y en la cordillera central del Tolima, radicó en la particularidad de los poblamientos de estas vertientes. Sin embargo, a fines del XIX y principios del siglo XX el Valle del Cauca logró iniciar un proceso de integración regional y desarrollar un proyecto industrial importante ${ }^{6}$. Así Antioquia y Valle, dos regiones que han podido apropiarse de su espacio e integrarlo a la vida local, regional y nacional han liderado el desarrollo industrial de Colombia a la vez que han fortalecido un espíritu empresarial que ha tocado a sectores pobres hasta llegar a fundar poderosas economías informales, que hoy combate el sector formal de la economía nacional. En conclusión, la experiencia, el carácter y la personalidad de una región no pueden ser transferidos a otras. Los fenómenos de identidad brotan de las creaciones de los hombres en su medio y se vuelven patrimonios históricos irrenunciables.

Estas disparidades internas de las regiones hacen rica su realidad y por ende la realidad colombiana. Pero al mismo tiempo nos alertan sobre aquello que predominó en uno y otro lugar. Dado el poco interés que la colonización del siglo XIX ha tenido para regiones distintas a la de Antioquia, intentaremos analizar algunos aspectos relacionados con el Caribe colombiano, en donde hubo un interés por los baldíos por parte de gentes importantes y una lucha de vecinos y vecindarios por defender las tierras que durante años habían explotado, sin haber tenido acceso a un título de propiedad.

\section{Ocupación de baldíos en la costa Caribe}

El proceso de ocupación de tierras baldías en la costa Caribe se acentuó, como en todo el territorio nacional, después de 1850. En el departamento del Magdalena las gentes se desplazaron hacia las jurisdicciones de Tamalameque, Aguachica y hacia los territorios controlados por los Motilones en un movimiento que buscaba el sur y el oriente de la región. También se desplazaron hacia el norte, en la jurisdicción de Santa Marta, en donde las solicitudes de baldíos fueron comunes por parte de grupos de colonos o de pequeños y grandes propietarios. Así, en Posigueica Manuel Díaz Granados recibió 300 hectáreas de tierra, a Jorge Ancízar en La Nevada se le concedieron 609 hectáreas y 4400 hectáreas en la Colonia Samper, mientras que Jh. Penon and Co. de París recibió 3000 hectáreas en Don Diego. Todos ellos entre 1893 y $1896^{7}$. Los baldíos de la jurisdicción de la ciudad de Santa Marta atrajeron el interés de nacionales y extranjeros, de tal manera que en 4 años 11 individuos obtuvieron 13.451 hectáreas de tierra.

Otros individuos estaban recibiendo sus títulos de terrenos cuyas extensiones desco-

6 Osear Almario García, La. Configuración moderna del Valle del Cauca, Colombia 1850-1940). Espacio, poblamiento, poder y cultura, Cecan editores, Cali, 1994.

7 A.G.N. (Bogotá), Baldíos 14, f.108r.; 15, f.153r. y f. 156r. 


\section{CUADRO 1 - ADJUDICACIONES DE BALDÍOS EN LA JURISDICCIÓN DE SANTA MARTA (1893-6)}

\begin{tabular}{|lcll|}
\hline NOMBRE & HECTÁREAS & $\begin{array}{c}\text { NOMBRE } \\
\text { DE PREDIO }\end{array}$ & AÑO \\
\hline Jorge Ancízar & 4400 & Colonia Samper & 1896 \\
\hline Jh. Penon And Co París & 3000 & Don Diego & 1893 \\
\hline Silvestre Samper Uribe & 1800 & La Paulina & 1896 \\
\hline Andrew Steward & 1000 & Onaca & 1896 \\
\hline P.H. Marshall & 900 & no dice & 1896 \\
\hline Jorge Ancízar & 609 & La Nevada & 1895 \\
\hline Joaquín Reyes & 600 & Tanjica/La Helena & 1896 \\
\hline William S. Crane & 380 & El Líbano & 1896 \\
\hline Manuel Díaz Granados & 300 & Posigueica & 1896 \\
\hline Orlando Flye & 216 & Constante & 1895 \\
\hline José A. de Andreis & 200 & Mamacasaca & 1896 \\
\hline José A Díaz Granados & 46 & No dice & 1896 \\
\hline Totales & $\mathbf{1 3 4 5 1}$ & & \\
\hline
\end{tabular}

Fuentes: A. G. N. (Bogotá), Baldíos 15: f. l'53r, 156r, 158r; 16: f. 103i; 104r, 106r, 108r, 109ry v, HOr, 117ryv, 119r, 125ry 129r.

nocemos. Pero la muestra del cuadro 2 no deja de ser ilustrativa del interés que los baldíos despertaban en esta región de Colombia. El interés no era sólo de gentes colombianas, sino también de extranjeros, incluidas algunas empresas. Por ejemplo, el señor Orlando L. Flye, como agente y apoderado de la compañía The West India and Colombia Telephone Company, solicitó la adjudicación de un terreno baldío llamado El Frasco, el cual necesitaba para ubicar la maquinaria de luz eléctrica de la ciudad de Santa Marta. El 13 de septiembre de 1893 se le adjudicó dicho terreno ${ }^{8}$. Este mismo individuo estaba recibiendo en 1896 otros baldíos que solicitó, tal como se ilustra en el cuadro 2.

Es indudable que esto no es más que una muestra del interés por los baldíos a finales del siglo XIX. Hubo muchos casos más cuyas peticiones aún no se habían resuelto. Tal vez un estudio sistemático sobre todas las peticiones realizadas a lo largo del siglo XIX permita conocer mejor la dimensión que alcanza-

8 A.G.X. (Bogotá), Baldíos 14, f. 1()6r. 
ron ciertos polos de desarrollo. Lo que sí puede inferirse es la dimensión de los predios, que no alcanzaban, en su mayoría, a superar las 5 mil hectáreas. Ello posiblemente por que las tierras baldías de este distrito no eran tan abundantes como en otras regiones alejadas de uno de los puertos más importantes de Colombia como era Santa Marta.

\section{CUADRO 2 ADJUDICACIÓN DE BALDÍOS EN LA PROVINCIA DE SANTA MARTA, 1896}

\begin{tabular}{|c|c|c|c|c|c|}
\hline NOMBRE & $\begin{array}{l}\text { NOMBRE DE } \\
\text { PREDIO }\end{array}$ & JURISDICCIÓN & TIPO & TíTUlo & FECHA \\
\hline Víctor Dugano & $\begin{array}{l}\text { El Mamey y } \\
\text { Lamedero }\end{array}$ & Dibulla & 1100 hs. & Adjudicado & 18-XII-96 \\
\hline Carlos H. Hurd & Las Nubes & Santa Marta & Terrenos & Adjudicado & $3-X I I-96$ \\
\hline Manuel Dávila & $\begin{array}{l}\text { La Macanilla, La } \\
\text { Colonia y Barán }\end{array}$ & Santa Marta & Terrenos & Concesión & 7-XI-96 \\
\hline $\begin{array}{l}\text { Manuel A. } \\
\text { Dangond }\end{array}$ & La Esperanza & Villanueva & Terrenos & Cultivador & 28-VIII-96 \\
\hline Luis J. Porto & Corralito & $\begin{array}{c}\text { San Juan } \\
\text { de Córdoba }\end{array}$ & Globo & Adjudicado & $24-X-96$ \\
\hline $\begin{array}{l}\text { Aniceto Fuentes } \\
\text { Nemesio Oñate } \\
\text { Aniceto Fuentes } \\
\text { Zamora }\end{array}$ & El Eneal & Villanueva & Tárenos & $\overline{\text { Provisional }}$ & 5-III-96 \\
\hline Celestino García & Santa Elena & Río de Oro & Globo & Cultivador & $22-11-96$ \\
\hline Ch. Gautier & San Carlos & Santa Marta & Baldío & Adjudicado & 7-II-96 \\
\hline WilliamS. Grane & Agua Sula & Santa Marta & Terrenos & Por títulos & $14-11-96$ \\
\hline Aurelio Linero & Marinea & Santa Marta & Baldíos & Adjudicado & 7-II-96 \\
\hline Orlando L. Flye & Cacagualito o la Eva & Santa Marta & Baldíos & Por títulos & $24-11-96$ \\
\hline $\begin{array}{l}\text { Antonio } \\
\text { Dangond }\end{array}$ & San Antonio & Villanueva & Terrenos & Adjudicado & 3-II-96 \\
\hline
\end{tabular}

Fuentes: A. G. N. (Bogotá), Baldios: f.102r, 105r, 107r, 113r, ll4r, 118r, 121n 130r, 131r, 132r, 133r, 134r. 
Importante también en este proceso de apropiación de tierras fue la participación de los colonos cuando decidieron confrontar los rituales de la titulación de baldíos y hacer oposición para que se les reconocieran los derechos adquiridos como cultivadores y poseedores de las tierras que pretendieron estos y otros señores. El juego de intereses entre sectores sociales totalmente opuestos constituye uno de los rasgos centrales del problema agrario vinculado a la concesión de baldíos. Las peticiones de extensiones medianas o grandes que hacían señores notables contrastan con los esfuerzos de los vecindarios y los colonos por defender sus pequeñas chacras o unas minúsculas posesiones. Este aspecto se estudiará luego de mirar lo que ocurrió en el Estado de Bolívar, en donde también se vivió una intensa demanda de tierras por parte de empresarios nacionales y extranjeros a partir de 1875. Tres núcleos ubicados al sur del Estado se convirtieron en polos de atracción y expansión: Montería, Caymito y Sucre. En sus jurisdicciones se entregaron más de 58 mil hectáreas en 28 adjudicaciones (véase Cuadro No 3). La muestra refleja los niveles de concentración de tierras entre empresarios notables de la región.

La demanda de baldíos en el Caribe colombiano presenta las dos grandes tendencias que predominaron en Colombia, una vez el Estado dictó las normas que regirían los derechos de los colonos y de los cultivadores que las hubieran mejorado, con casa de habitación, cultivos, cercas y desmontes y que tuvieran capacidad para pagar un agrimensor que deslindara los terrenos pretendidos y levantara unos planos de los mismos. La primera gran tendencia fue la participación de empresarios interesados en obtener unidades mayores de tierra, mientras que la segunda la constituyó el esfuerzo realizado por colonos pobres interesados en acceder a una pequeña parcela o en quedarse en las tierras que habían cultivado como arrendatarios o como trabajadores perdidos en el bosque durante décadas. Pero no sólo fueron estos dos extremos de la pirámide social los que aprovecharon las ventajas de la ley. Entre ellos surgieron medianos tenedores, interesados también en ampliar las áreas mínimas que habían sido fijadas por la ley, esforzándose en titular 50, 100 o 200 hectáreas. Esta redistribución desigual de la tierra baldía del Caribe, pone de manifiesto y valoriza el poder de la iniciativa personal, a la vez que da fe de que en una sociedad que privilegia la libre empresa, no es posible pensar en redistribuciones iguales de los recursos, como lo era en este caso la tierra.

Las concesiones indicadas en el cuadro 3 muestran el interés por los baldíos de la jurisdicción de Montería y de la banda occidental del río Sinú. Allí, 17 individuos recibieron 44.243 hectáreas, es decir, el 76\% de las tierras que se adjudicaron en 20 años, del último cuarto del siglo XIX. Entre tanto en San Benito, Chinú y Caymito se entregaron 8.113 hectáreas a 7 individuos, mientras que un empresario pidió 7.958 hectáreas en Retiro-Sucre. Se podría deducir de esto que las tierras baldías que más interés despertaron fueron las de la jurisdicción del Sinú, es decir, el actual departa- 
BALDÍOS

\section{CUADRO 3 CONCESIONES DE TIERRA HECHAS EN EL ESTADO DE BOLÍVAR (1875-1893)}

\begin{tabular}{|c|c|c|c|}
\hline ADJUDICATARIO & HECTÁREAS & REGIÓN & AÑ̃o \\
\hline Antonio Pineda y Navas Hermanos & 7958 & Retiro -Sucre & 1875 \\
\hline Antonio Pineda y Navas Hermanos & 423 & San Sebastián & 1875 \\
\hline Manuel Antonio Pineda & 2112 & San Benito Abad & 1875 \\
\hline José de los Santos Hoyos & 1262 & Caimito - Ayapel & 1875 \\
\hline Ventura y Manuel García & 594 & San Sebastián & 1875 \\
\hline Gilie Mathieu & 1268 & Caymito-Mompox & 1878 \\
\hline $\begin{array}{l}\text { Manuel Antonio Pineda, Marcelino, } \\
\text { Concepción y Santiago Santos }\end{array}$ & 3175 & Montería & 1879 \\
\hline Gilie Mathieu & 1183 & Caymito-Mompox & 1881 \\
\hline Merlano y Henríquez & 100 & Lorica & 1881 \\
\hline Luis Verbrugghe & 5006 & Montería & 1883 \\
\hline Domingo Vergara & 1496 & Chinú & 1883 \\
\hline José M. Ballesteros y Mauricio Vertel & 1207 & Montería & 1883 \\
\hline Angela de Echeva & 801 & Montería & 1883 \\
\hline AlbertLacheme & 828 & Montería & 1883 \\
\hline Rudecindo Sánchez & 655 & Montería & 1883 \\
\hline Miguel Vega & 559 & Montería & 1883 \\
\hline Juan R. Negrette & 437 & Montería & 1883 \\
\hline Manuel N. Martínez & 423 & Montería & 1883 \\
\hline Francisco de J. Lora & 414 & Montería & 1883 \\
\hline Toribia Posada de Díaz & 409 & Montería & 1883 \\
\hline Salvador Gamarra & 269 & Chinú & 1884 \\
\hline A.L. Boiteau y Cía. & 5440 & Montería & 1884 \\
\hline David Logan y Tomás Walter & 2280 & San Carlos & 1884 \\
\hline Manuel N.Jiménez & 3238 & Montería & 1884 \\
\hline Feliz Panzani & 4999 & Montería & 1890 \\
\hline Pablo Duran & 4989 & Montería & 1890 \\
\hline David Mercado & 2300 & Montería & 1893 \\
\hline Juan Gómez & 4703 & Banda Occ. del Sinú & 1893 \\
\hline Total Hectáreas & 58522 & & \\
\hline
\end{tabular}

Fuentes: Diario Oficial, Números 3059,3410, .3444,3457,3462,4230,5059,5090,5777,5867,5896,5915,5970,6043,6095,8022,8287,9273. 
mentó de Córdoba. Se estaba consolidando allí una gran propiedad cuyo destino sería el refugio de trabajadores desposeídos que engrosarían los cuadros de los primeros asalariados rurales del siglo XX.

Estas concesiones representan una muestra global de las tierras adjudicadas en el Estado de Bolívar. Indudablemente no están ahí todos los baldíos feriados en esta región. Otros peticionarios habían recibido tierras antes de 1875 y solicitaron otras después de 1894. Incluso hubo quienes recibieron tierras al efectuarse las oposiciones por encontrarse las suyas dentro de globos mayores adjudicados por el Estado. Por ejemplo, el terreno solicitado por Juan Gómez denominado Pirú, tenía 47.029.200 metros cuadrados (4.703 hectáreas). Dentro de ellas se incluyeron 314.000 metros cuadrados (31,4 hectáreas) pertenecientes a Nicolás Velásquez, de los cuales 14000 (1,4 hectáreas) estaban cultivados y 300.000 (30,0 hectáreas), como resultado del derecho que le daba la naturaleza del cultivo. ${ }^{9}$

Estos casos, cifras, volúmenes y peticiones apenas constituyen un signo sobre el impacto que las leyes agrarias tuvieron en la transformación de la posesión y de la propiedad de las tierras, de modo especial en aquellas que estaban ubicadas en lugares de dudosa titulación. De otro lado contienen las estructuras del cambio asumido por quienes nunca concibieron la tierra o su parcela como un recurso de riqueza o como un bien personal que sólo existía en tanto que una institución pública entregara el testimonio de su registro ante las autoridades competentes. Finalmente, la divulgación de las leyes dictadas por el Estado actuó como contenedor de una avalancha de abusos propia de una sociedad estratificada, prepotente y racista. La presencia del Estado no sólo mediante jueces y alcaldes municipales, sino de gobernadores y del mismo Ministerio de Hacienda, le otorgó un sustrato de legitimidad para evitar una colonización sangrienta.

Durante el siglo XIX la fuerza se sustituía con la malicia y con juegos de gallina ciega se trataba de imponer el interés personal. Los hombres actuaban con sigilo en los tribunales y cuando los agrimensores y revisores oculares caminaban bajo los arbustos y el sol o entre la yerba y las cañadas para verificar y trazar los linderos, los peticionarios maliciosos y furtivos se esforzaban para que la luz del día los hiciera invisibles ante los ojos de los labradores que iban a ser expropiados. Es cierto que hubo alianzas entre autoridades y solicitantes de baldíos, pero la opción de acudir a las instancias más altas del Estado hacía que un acto de expropiación e injusticia triunfara por mera manipulación de la ley y de sus mecanismos de operación. Esta lección de presencia del Estado al momento de feriar las tierras nacionales y hacer cumplir las leyes de baldíos era coherente con su decisión de beneficiar no sólo a los

9 A.G.X. (Bogotá), Baldíos 14, ff.38r - 42r 
grandes señores y a los poderosos, sino a los menos favorecidos de la fortuna. Es justo rescatar también la función y el compromiso de quienes improvisaron con sus escritos y alegatos la difusión de los derechos de los iletrados. Abogados y leguleyos se unieron para que las leyes $6 l$ de 1874 y 48 de 1882 se metieran por las rendijas de los bosques de Colombia y respaldaran a un campesinado poco versado en tener que sacar una fe de bautismo y de confirmación para sus granjas si no querían ser expulsados por las sendas vacías e inciertas de la frontera inhóspita.

\section{Herederos y pretendientes sin fortuna}

En medio de este juego de peticiones, de concesiones y de amparos elevados ante las instancias de la administración municipal, distrital, departamental o nacional se encuentran quienes al heredar tierras y hacer valer sus derechos fueron rechazados por labriegos, que alegaron su condición de colonos y la naturaleza baldía de las tierras que trabajaban en contra de los derechos defendidos por estos infortunados herederos de turno. Veamos un ejemplo.

Después de morir don Manuel Arias en el vecindario de Ocaña, su hija Adelaida Ibáñez de Peña supuso que el lote de tierra denominado Neorán, que pertenecía a la jurisdicción de Aguachica, era de su propiedad. La posesión de dicho terreno había sido otorgada a su padre, por el Juez de Aguachica quien actuó como comisionado del Juez segundo del circuito de Ocaña. ${ }^{10}$ Por algún rumor que circuló entre los trabajadores de Neorán, estos visitaron o fueron visitados por un letrado, quien redactó un memorial dirigido al Ministerio de Hacienda, en donde se pedía amparo y reconocimiento de estas tierras como de propiedad de la Nación. Era el 3 de febrero de 1894, cuando los 64 reclamantes firmaron un texto, cuya argumentación jurídica se fundaba en lo ordenado en las leyes $6 \mathrm{l}$ de 24 de junio de 1874 y 48 de 28 de agosto de 1882 que, en esencia, estipulaban que los cultivadores de baldíos establecidos con casa y labranza no podían ser perturbados en la posesión si no existía sentencia enjuicio Civil ordinario. Los 10 colonos letrados y los 54 iletrados, que firmaron a ruego el Memorial, pedían al juez municipal una información sumaria sobre la cuestión en disputa. ${ }^{11}$

Sin embargo, una semana antes el señor Manuel Cabiedes, con el fin de comprobar ante el Ministerio de Hacienda que la Señora Adelaida Ibáñez de Peña no tenía derecho al globo de tierra denominado Neorán, suplicó al Juez de Aguachica que llamara a 5 testigos para que respondieran un interrogatorio de 6 preguntas sobre los derechos a dicho terreno. Los cinco hombres mayores de edad, agricultores, vecinos del distrito y católicos fueron llegando hasta el Juzgado entre el 20 de enero y el 1 de

10 A. G. N. (Bogotá), Baldíos 15, ff.396r.v.

11 A. G. \. (Bogotá), Baldíos 15, ff.396r. a 398v. 
FRONTERAS • No. 1 / VOL. 1 / $1997 \bullet$

EL CARIBE COLOMBIANO SIGLO XLX PRINCIPALES LUGARES MENCIONADOS EN EL TEXTO

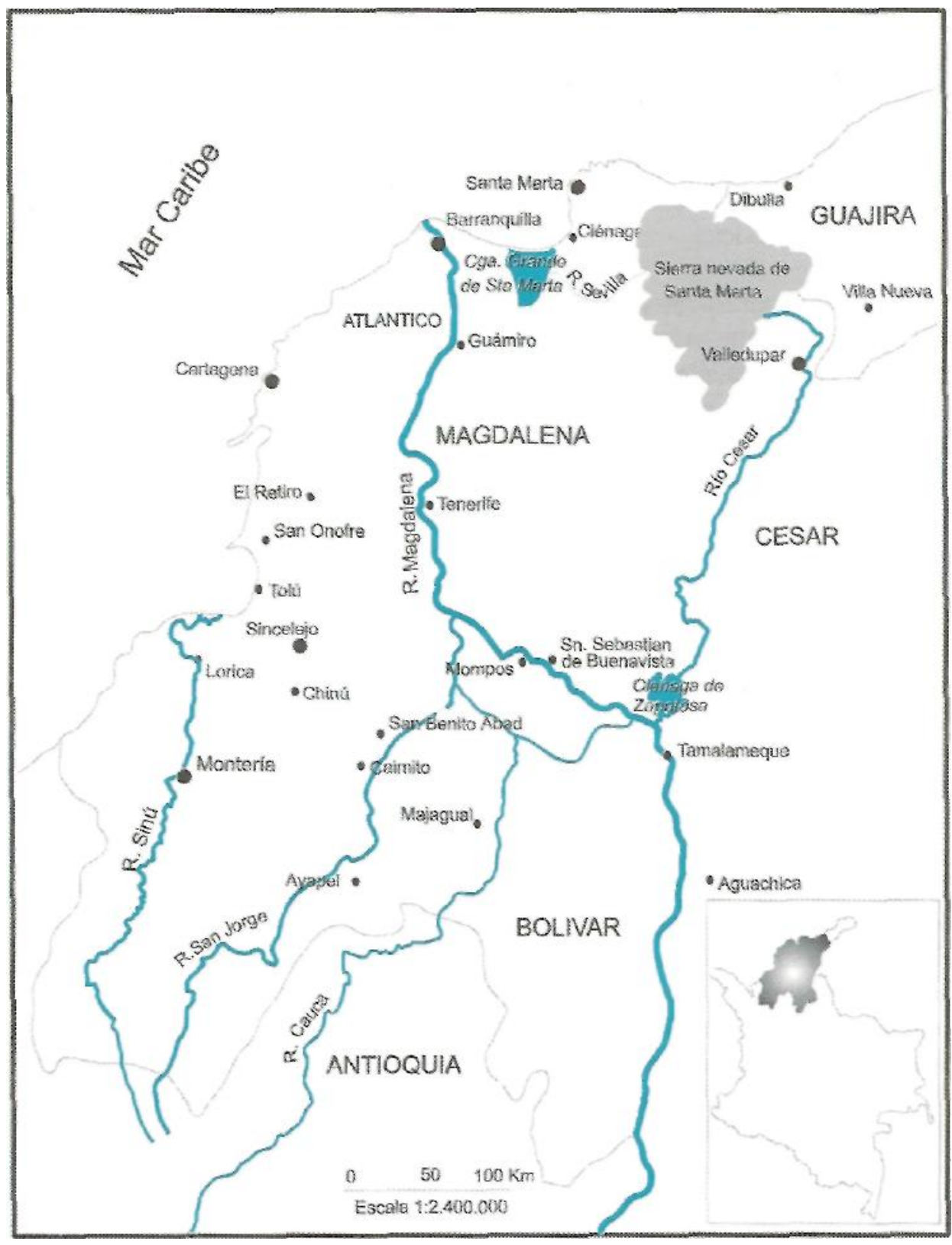

c/o H.T.P.

Dibujo:A.M. Jara

$-45-$ 
febrero de 1894. Sin ninguna expresión creativa o imaginativa se limitaron a ratificar los contenidos de las preguntas. De sus afirmaciones secas, pero juramentadas previamente, se concluía que hacía 40 años no se conocía dueño alguno del globo de tierra Neorán, el cual era tenido por baldío y estaba ocupado por más de 400 colonos, "que todos ellos tienen casa de habitación, café, cacao [y] cañas de azúcar" Finalmente repitieron con unanimidad pasmosa que toda esta gente estaba allí hacía más de 20 años. ${ }^{12}$ La uniformidad de sus respuestas no significa un compromiso con la verdad, pero sí le abre un interrogante al unanimismo de estos iletrados. Puede ser que sus sentimientos de solidaridad sean ajenos a toda sospecha. Lo cierto es que como testigos garantizaban la razón de una petición y contribuían a ciarle solidez o inconsistencia a la ley.

Lo real es que para la historia, el cálculo, el silencio y la parquedad de estos testimonios abren fisuras a las sendas de la certidumbre. Más allá de lo textual, sobreviven procesos cimentados en otros espacios que la fórmula que interroga devela. Así parece ser más importante lo que se pregunta que lo que se responde. La verificación de una verdad conduce no sólo a la certidumbre de lo interrogado, sino que la respuesta esconde otras verdades apenas reconocidas en el lenguaje. Ojalá que el recurso de la semiótica nos acerque con sus métodos a las bahías ocultas del signo y las palabras.

Irritada por la actitud de los colonos, o tal vez por prepotencia, por falta de tacto o por intemperancia, la señora Adelaida Ibáñez de Peña escribió al Ministerio de Hacienda el 2 de marzo de 1894, para que no se declarara baldío el terreno Neorán, pues cuando fue recibido por su ascendiente no tuvo oposiciones de ningún interesado, conforme lo estipulaba la ley. Convencida de su legítimo reclamo explotó, y escribió a continuación que el Señor Ministro de Hacienda "carece de autoridad para decidir si tengo o no derecho" sobre mis bienes. La respuesta fue rápida y oportuna. El ministro manifestó que la ley ordenaba amparar los terrenos baldíos que hubieran sido ocupados de buena fe, por más de 4 años, con cultivos y casas. Igualmente, que la ley exigía a los dueños presentar los títulos de propiedad en que se fundaban sus derechos y solicitaba que ellos se remitieran a su despacho. Mientras tanto se amparaba a los colonos. ${ }^{13}$ El 3 de marzo el Ministerio de Hacienda transcribió el memorial de los colonos a la gobernación para que amparara de oficio a los "reclamantes en la posesión de los terrenos que ocupan con cultivos y casas de habitación", mientras la señora Adelaida Ibáñez acreditaba sus títulos. ${ }^{14}$ No se sabe en qué concluyó este pleito, que quedó entonces en statu quo.

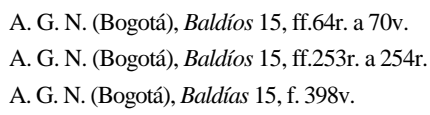


Pero no siempre los colonos encontraron el apoyo de las autoridades locales, al igual que el conflicto social no estuvo determinado por la pretensión de acceder a grandes extensiones de tierra. Cualquier autoridad a nivel local podía obstaculizar un reclamo de posesión del mismo modo que cualquier tipo de extensión podía generar memoriales y alegatos jurídicos. Con esto queremos poner de presente que la colonización del siglo XIX no puede reducirse a una mera disputa entre grandes poseedores y trabajadores desposeídos. Todos los actores sociales metidos en los baldíos o quienes alegaron el carácter público de sus tierras ingresaron a este remolino de reclamos, oposiciones y peticiones de justicia. La cuestión agraria en estas fronteras se expandió de tal manera que la sociedad en general se vio conmocionada por este proceso de apropiación.

Hubo casos como el de Tierra Nueva, en jurisdicción de San Juan del Córdoba, Magdalena, que enfrascó a seis colonos en una disputa jurídica contra Eugenio García, por un pequeño globo de tierra. Los textos de los memoriales y alegatos ponen de presente que lo que se defendía no era sólo una pequeña parcela, sino la transformación de un mundo, el valor de unas herencias y sobre todo el sentimiento de justicia contra alguien que pretendía devorar toda la historia de esfuerzos y trabajos para adecuar 80 fanegadas de tierra. Estas labores de adecuación y aterrazamiento, calificadas de heroicas por estos labradores, se convertían en un patrimonio moral que legitimaba sus derechos y por ende sus reclamos.

Para los colonos, Tierra Nueva había brotado del caos que regía las entrañas de la naturaleza misma. Los ríos Aracataca y Pájaro se perdían en las sabanas envolviendo entre sus aguas un mundo primigenio de árboles y animales. Cedros, buitres, serpientes y caimanes se redistribuían por entre las tierras anegadizas haciendo insoportable e insufrible la existencia. A ello se unía el clima del trópico que envolvía todo este paisaje de "verde apariencia", y de calores "deletéreos". Este rigor del medio era visitado por huracanes, que con su lenguaje de vientos incontenibles, contribuían a derribar árboles robustos sobre los cauces naturales de los ríos para darle nacimiento a un mundo de aguas, sedimentaciones y detritus. ${ }^{15}$

Y llegaron los hombres, los colonos, para introducir el orden en este universo y acabar de llenar de sedimentos el pantano, liquidar el mundo salvaje y tomar los ríos a sus cauces naturales, para depositar sus lenguas de agua sobre la Ciénaga Grande. El río Aracataca y el río Pájaro volvieron a sus lechos primitivos, para ceñir el cuerpo de 80 hectáreas convertidas en fincas después de una labor incesante y de mejorarlas con cultivos de caña de azúcar, plátano, yuca, maíz y pastos artificiales. El trabajo de

15 A. G. N. (Bogotá), Baldíos 15, ff.342r.v. 
estos colonos había logrado no sólo construir cercas permanentes y casas de habitación, sino levantar un caserío bastante poblado en donde residían las familias de estos campeones de la civilización. ${ }^{16}$

Este relato, que nos pinta dos paisajes, revela otra parte de la historia de la colonización en Colombia no sólo en el siglo XIX sino en el siglo XX. Incluso nos advierte sobre todo el sistema de colonización operado desde el siglo XVI. Hay aquí una revelación histórica sobre el cambio de un estado a otro. La colonización se vuelve objeto de conocimiento en tanto que podamos explicar cómo se civilizaron las montañas, las selvas y las llanuras. Pero este movimiento operado entre entrar, transformar y cultivar remite esencialmente a la ecología. La historia de la colonización se convierte entonces en una historia del medio ambiente, pues ella nos cuenta cómo los hombres cambiaron el paisaje para fundar otro mundo. La destrucción de un universo regido por las leyes de la naturaleza, para colocar en él otro regido por la voluntad y el capricho de los hombres. La forma como cada cosa era destruida y cómo se reconstruía el medio, será el mejor encuentro con el movimiento, con el tiempo y con la cultura de unas sociedades que emergen de toda esta transformación.

Fueron estos nuevos paisajes los que pretendía el Señor Eugenio García. El venía a adueñarse del nuevo orden ecológico, y comenzó a cobrar arriendos a los colonos y a celebrar contratos con interpuestas personas que llevaron hasta Tierra Nueva sus ganados para que destruyeran las sementeras de sus moradores. La queja sobre esta pretensión de despojo recibió el apoyo del Ministerio de Hacienda que, el 5 de junio de 1894, solicitó un amparo de posesión en favor de los colonos. Para ello había sido necesario adelantar una investigación con todos los rituales y testigos establecidos por la ley. ${ }^{17}$ Nuevamente el statu quo o dejar las cosas como estaban al iniciarse el conflicto, había sido la fórmula aplicada a una disputa cuya resolución final también desconocemos. Lo importante de estos casos es señalar cómo el proyecto agrario del siglo XLX impulsado por el Estado invadía otras regiones diferentes a las que ocuparon la cordillera central y sus vertientes.

\section{Los baldíos y los vecindarios}

La titulación de grandes extensiones de tierra puede conducir a la apreciación de que hubo procedimientos fáciles y sencillos para la obtención de los baldíos. En esta convicción hay algo de verdad, pero también algo de equivocación. Se debe tener en cuenta que no todos los peticionarios actuaron con honestidad. Cuando se utilizaron triqui-

16 A. G. N. (Bogotá), Baldíos 15, ff. 342v. y 378r.v.

17 A. G. N. (Bogotá), Baldíos 15, ff. 343r. v. y 378r. a 383r. 
ñuelas, mentiras o se quiso proceder con malicia, las titulaciones fueron objeto de reparos y objeciones por parte de quienes se consideraron engañados, ignorados o maltratados. En este juego de gestos y actitudes merecen rescatarse las disputas que sostuvieron colonos que fueron incorporados en peticiones de globos y terrenos como si fuesen parte de la naturaleza baldía de Colombia. También merece conocerse la actitud de los vecindarios, cuyos caseríos sirvieron de ejes de sometimiento de tierras, pretendidas luego por individuos de todo género. Estos caseríos controlaron un espacio de vicia comunitaria y se expandieron hacia los baldíos para dar sustento a sus habitantes. Su estructura poblacional definida por la irregularidad de sus viviendas, sirvió para amontonar los días de migrantes perdidos o de arrendatarios, que más que una traza conocida, lo que intentaron fue darle estatuto y diseño a sus propias ilusiones. Unos casos pueden ilustrar esta dinámica de poblamiento y posesión de tierras.

Pudo ser de buena fe la petición que realizó en Cartagena don Andrés Gómez para que se le adjudicara un terreno baldío de 322 hectáreas, en el Distrito de San Onofre, entre las haciendas Angola, Majagual, Comisario y Labarcés. Sin embargo, al publicarse los edictos se presentó como opositor y en nombre de los vecinos del caserío de Pajonal el presidente del Consejo Municipal. El funcionario había actuado por presión o "excitación" que le hicieron los vecinos, para que los representara y objetara la petición. Esto obligó a la gobernación a realizar una inspección ocular de las tierras pretendidas por Gómez. ${ }^{18}$ De tal inspección se dedujo que el globo involucraba los caseríos de Santa Elena, Buenaventura, Lata y Pajonal y estaba cultivado de rozas, paja y árboles frutales de donde se abastecían los vecinos de dichos caseríos, quienes "por lo visto necesitan el terreno no cultivado aún para beneficio de todos ellos". En consecuencia, la decisión oficial sostuvo que la adjudicación no podía efectuarse "en lo tocante a la parte cultivada que es la mayor", pues dejaría a los cultivadores "sin tierras libres de uso común" para ejidos y nuevas poblaciones. Visto lo cual se resolvió no adjudicarle a Gómez dicho globo de tierra decisión que fue avalada por el Ministerio de Hacienda, ${ }^{19}$ en marzo 3 de 1896.

Otras concesiones se hicieron sin tener en cuenta los intereses de las poblaciones circunvecinas y de los pobladores de la región. Por ejemplo, los vecindarios de Media Luna y Remolino y el del caserío San Sebastián del Bongo se quejaron en 1878 por la adjudicación del globo "El playón del Gallinazo" a José de Jesús Rada. Los vecinos alegaban que la adjudicación de 672 hectáreas no tenía en cuenta las necesidades de 300 pobladores, a quienes se les expropiaba de los terrenos que necesitaban para sus crías y labranzas, ${ }^{20}$ sin derecho a indemnización. Las quejas de estos colonos generaban conmoción en la localidad que entraba en estado de agitación política y social. La vida de los poblados se activaba para iniciar un recorrido hacia el

18 A. G. N. (Bogotá), Baldías 16, ff. 68r.v.

19 A. G. N. (Bogotá). Baldíos 16, ff. 69r.v.

20 A. G. N. (Bogotá), Baldíos, f. 358r. 
pasado, desde donde saldrían los más sólidos argumentos de los derechos de estos colonos. A veces, no bastaban sus quejas sino que era necesario comprometer los poderes locales, que siempre estaban atentos a tomar partido por aquello que representara mejor los intereses de las aldeas y de los caseríos.

Así, en 1879, el mismo alcalde de la parroquia de Guaymaro se vio precisado a intervenir en defensa de sus vecinos, afectados por la citada adjudicación. El expresó que el vecindario se encontraba en posesión de dicho Playón desde 1876, aunque lo cultivaban desde hacía más de 30 años, como oriundos que eran de dicha parroquia. Para este funcionario, el señor Rada era un perturbador, pues a pesar de saber que el playón estaba poblado y cultivado, lo había pedido en adjudicación. Por ello y conforme a lo dispuesto por la ley debía decretarse la nulidad de dicha concesión. ${ }^{21}$

Lo específico de estos reclamos de vecindarios de la costa, aliados con sus autoridades, radica en la capacidad de intervención del Estado que estaba atento a imponer los criterios legales vigentes. Los colonos de la costa Caribe de Colombia no sólo defendían la posesión previa de las tiercas, como lo hicieron otros colonos de los Andes y de sus vertientes, sino que desde sus propios poblados intentaban legitimarse como poseedores y propietarios de las tierras circunvecinas. Esto introduce un modelo de apropiación de baldíos que difiere de lo ocurrido en Antioquia o en las aldeas del Tolima. En Antioquia los pueblos fueron creados por grandes latifundistas y empresarios que distribuyeron la tierra a colonos, traídos para valorizar la frontera, mientras que en el Tolima los colonos fundaron las aldeas a las que se les asignaron los baldíos para ellos y para quienes llegaran. En la costa Caribe los colonos generalmente no planearon realizar fundaciones de pueblos, los caseríos resultaron de la tendencia de las gentes dispersas a congregarse en comunidades. Allí fueron encontrados por quienes llegaron con pretensiones de apropiase de sus labranzas y de expulsarlos de ellas.

En este tira y afloje por acceder a los baldíos o por permanecer en ellos surgieron actores sociales que aprovecharon la situación para cambiar su posición, ya Riera dejando de ser arrendatarios para convertirse en colonos, o dejar de ser meros trabajadores flotantes para convertirse en productores sedentarios. Estos fueron algunos de los efectos que produjo la legislación vigente y la voluntad política de poner en venta los bienes baldíos de la República. De la difusión de la ley surgió la pretensión de herederos de viejos arrendatarios de convertirse en propietarios, alegando que las tierras eran baldías y dejando de pagar las rentas que sus antepasados habían estado obligados a cancelar. En la lucha por la titulación de las tierras, la conversión de arrendatarios en colonos sería un instrumento de conflicto bastante profundo a finales del siglo XIX.

21 A. G. N. (Bogotá), Baldíos 2, f. 358r. 
Los casos de Banco Colorado y Guataca ilustran lo que la ley sobre baldíos fue capaz de desatar entre múltiples actores de una sociedad rural. Estos dos terrenos pertenecieron a la compañía de Jesús desde 1643. Luego de su expulsión en 1767, ${ }^{22}$ la propiedad tuvo diversos dueños hasta que en 1811 cayó en manos de don Mariano y don José Gabriel Amaris y Pedroso. Cuando pertenecían a los Jesuitas los terrenos citados se dieron en arriendo a varias personas y se reservaron algunas partes para ser trabajadas con sus esclavos o para apacentar ganados. Este sistema de explotación tuvo durante el siglo XIX un cambio fundamental, al reemplazar "el trabajo del esclavo, por el trabajo del hombre libre al servicio del dueño de la hacienda", dando lugar a "que muchos de los arrendatarios construyeran sus casas" al lado del "Caño de Guataca" para estar más inmediatos a sus labranzas. ${ }^{23}$ Por esta razón, se formó en tal punto el Caserío de Guataca, cuyos moradores eran descendientes de los que desde el siglo XVIII venían trabajando como arrendatarios en dichos terrenos. Los moradores de Guataca, según el dueño, se hacían los desmemoriados, para considerarse cultivadores con casa y labranza en tierras baldías, no obstante ser ellos mismos, en la actualidad, arrendatarios. ${ }^{24}$

El cambio de actitud de estos trabajadores agrarios había surgido hacia 1840 cuando se negaron a pagar sus rentas. Esta decisión arrastró a varios vecinos de Guataca a asumir la misma actitud en 1844 alegando que las tierras en donde laboraban eran baldías. Los procesos de compra y venta de mejoras se activaron y los nuevos dueños radicalizaron sus posturas frente a los rentistas. Por ejemplo, Domingo Agamez compró al arrendatario Cipriano Tovar las sementeras de plátano, caña de azúcar y yucas. $\mathrm{Al}$ negarse a continuar pagando las rentas, puso a prueba la validez de los títulos de don Mariano Amaris y Pedroso, quien en los tribunales consiguió una sentencia condenatoria contra las pretensiones de Domingo Agamez. ${ }^{25}$ Los arrendatarios procedían, por efecto demostración, a actuar del mismo modo que los propietarios, quienes iban vendiendo las tierras y generaban derechos de propiedad. Así, Mariano y José Amaris Pedroso compraron en 1811 las tierras a José Ignacio del Campo, quien a su vez las había adquirido en 1800 de José Antonio Martínez Pedroso. ${ }^{26}$ Por ello alegaron que se revocara la resolución que declaraba baldías dichas tierras, pues los vecinos de Guataca no tenían título legal sobre ellas. ${ }^{27}$

Los años que siguieron a estas primeras refriegas jurídicas trajeron nuevos juicios civiles, que se fueron acumulando hasta que en 1888 el vecindario de Guataca se

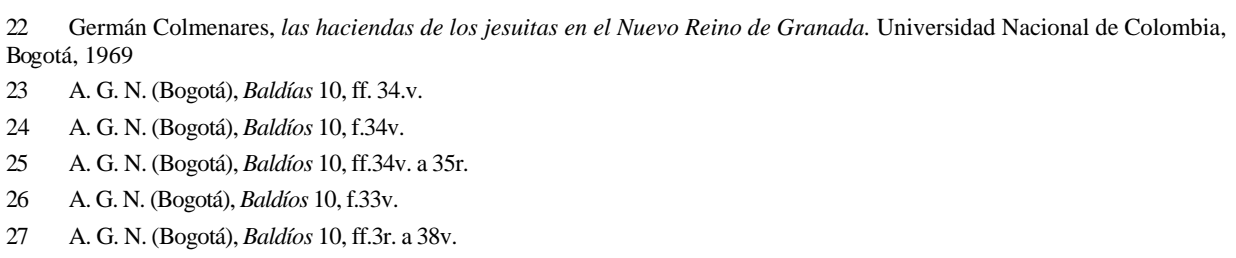


valió de las autoridades de policía para que lo protegiera en la posesión de las tierras ocupadas. La intervención de la fuerza pública hizo que se aumentaran los argumentos de los rentistas, quienes manifestaron que el apoyo de la autoridad se hacía sin "tener en cuenta que a su vez deja en la miseria a los que despoja de lo que legítimamente les pertenece" sentando terribles precedentes de desprestigio a la columna del orden social, como era la propiedad. Los arrendatarios se valían de la ley 48 de 1882 y de normas precedentes que protegían la posesión y el trabajo de tierras no tituladas y baldías. Por ello las autoridades locales les arropaban en su acción. ${ }^{28}$ El Estado servía así de mediador en estos conflictos de posesión - desposesión que fueron comunes a lo largo del siglo XIX.

Como no quedaba más que la argumentación de los abogados, ellos alegaron que los arrendatarios pretendían destruir el derecho que asistía a los legítimos propietarios. De sus argumentos se desprende que Banco Colorado y Guataca en realidad constituían una misma heredad denominada Barranco. No eran pues dos lotes, sino una unidad de unas 5000 varas cuadradas (624 fanegadas o 400 hectáreas). ${ }^{29}$ Dentro de este terreno se habían fundado dos haciendas valiosas llamada la una Molina y la otra San Mateo, la primera de don Osear A. Trespalacios Cabrales y la segunda del señor don Dimas Pontón, quienes eran arrendatarios de la familia Pedroso. ${ }^{30} \mathrm{La}$ aceptación de los reclamos de los arrendatarios por parte del Estado ponía en entredicho la propiedad privada y estimulaba que otros arrendatarios actuaran por la misma vía desconociendo a sus arrendadores.

El caso de Guataca corrobora una vez más el poder de agitación que las leyes de baldíos y protección a colonos tuvieron entre algunos sectores sociales de la costa Caribe de Colombia. ¿Hasta dónde el interés de una justicia social deterioró las relaciones sociales establecidas y contribuyó a dimensionar la participación de unos y otros en las guerras civiles de finales del siglo? De otro lado es importante observar cómo el tránsito de la Colonia a la República generó unos poblamientos, que como el del Caño de Guataca, iría a servir de eje a las disputas sostenidas por su vecindario contra viejos hacendados de origen colonial. La hacienda no se descompuso en pequeñas propiedades como se supondría, sino que permitió la creación de un poblado, de unos arrendatarios y de unos terrajeros negros. La evolución social contribuyó al fortalecimiento de nuevas haciendas, mientras que la ley de baldíos se convirtió en el recipiente jurídico que cocinó los derechos que los arrendatarios alegarían en contra de los propietarios. Nos queda por saber qué pasó con los terrajeros negros, que también trabajaban la tierra en pequeñas chacras antes de su liberación en 1852.

A. G. N. (Bogotá), Baldíos 10, f.35r. a 36v.

A. G. N. (Bogotá), Baldíos 10, f.33r.

A. G. N. (Bogotá), Baldíos 10, f.34v. 
La presión por las tierras llegó incluso a afectar los ejidos. El secretario de hacienda de Santa Marta advertía que "El deseo de poseer terrenos se generaliza". De inmediato ponía de presente como dicha presión había entrado a las tierras de los mismos municipios, pero no sólo por intereses económicos, sino por fenómenos poblacionales. Decía que "A la gobernación han venido memoriales de varias poblaciones en quejas por causa de sus ejidos" y consultas sobre si era posible reemplazarlos cuando eran incorporados al área de la población para ser repartidos ${ }^{31}$. El proponía someter la cuestión al Congreso o al Consejo de Estado pues era evidente que:

a. Los ejidos que debía tener una población no podían ser iguales "pues los ejidos de una población de 50 mil habitantes deben exceder en nueve tantos a los de una población de 5.000".

b. Se requería de un procedimiento para solucionar los problemas de una población que había crecido y los había tomado para satisfacer su expansión.

c Las municipalidades que se veían precisadas a defender sus ejidos "carecen de norma para saber hasta qué punto o extensión pueden litigar su derecho." ${ }^{32}$

Los interrogantes ponen de presente cómo el fenómeno agrario había llegado también a las municipalidades que ante el hecho irreversible de las "invasiones" que realizaban sus habitantes tenían que defender no solo a su población sino a sus propias tierras comunales. Fue común a fines del siglo XLX una presión sobre este tipo de tierras por parte de colonos que se ubicaron en áreas en donde las tierras disponibles se agotaban por adjudicación o acaparamiento derivados de la política de entrega de baldíos.

\section{CONCLUSIONES}

El proceso de ocupación de los baldíos es apenas un referente central para quienes estén interesados en el estudio del problema agrario de la costa Caribe en el siglo XLX. Pero se debe admitir que los baldíos no definen por sí solos la historia de la producción, la circulación y el consumo del sistema agrario del Caribe colombiano. Una imagen complementaria debe buscarse en las empresas que fueron seducidas por la ganadería, el tabaco, la caña de azúcar, el algodón y el café. Para ello las notarías y los archivos particulares esperan que quienes se interesan por la investigación de esta región les inciten a hablar. Una unidad de producción o un conjunto de unidades pueden ampliarnos el horizonte sobre las formas de organización de la economía agraria.

Pero la cuestión agraria relativa a los baldíos remite a otro problema que debería profundizarse con pasión, pero sin apasionamientos derivados de sentimientos ideo-

31 A. G. N. (Bogotá). Baldíos 16, f.l39r.

32 A. G. N. (Bogotá), Baldíosl6, ff.!38r. v. 
lógicos o pretensiones políticas personales. Se trata de los procesos de titulación de tierras que tuvieron lugar en el siglo XIX, de modo especial entre los sectores pobres de la sociedad. Esto permitirá dilucidar el impacto social de las leyes de reforma agraria y, sobre todo, el impacto que tuvo para la economía colombiana.

Se ha hecho referencia a un tema que aún no abocamos. Es el del peso y el drama de la destrucción de los recursos naturales. La colonización debe ser estudiada mirando también los costos ecológicos de una política de bienestar e incremento de la productividad. A los costos de tal política hay que imputarle el capital dilapidado en la destrucción de bosques, aguas y especies biológicas de todo género cuya reposición no es ni será posible. No se puede seguir leyendo los memoriales de los colonos como proclamas contra la injusticia y como testimonios de los derechos de hombres dinámicos y emprendedores. El costo de la colonización tendrá que calcular todos estos bienes consumidos y destruidos para beneficio de unos sectores sociales, de unas generaciones y en detrimento de otras. Los memoriales esconden la racionalidad que imperó en el siglo XLX entre los políticos y los diligentes de Estado, así como de gremios y empresarios para quienes era necesario destruir la naturaleza para construir una sociedad con bienestar. ¿Pero valió la pena tanta destrucción frente a lo que se construyó como proyecto social? Un comentarista de 1871, frente al desastre de la naturaleza, decía: "la tala estúpida y al ocaso de los bosques nacionales, no puede dar de sí sino una lamentable devastación, que la generación siguiente no más, nos habrá de reprobar amargamente". Y al comentar las ventajas económicas de esta empresa manifestó:

"que hoy se esporte mucha quina, mucho caucho etc, que entren en circulación tantos valores estancados en el fondo de las montañas; la Nación nada pierde con esto; porque los valores esportados ocasionan un retorno de importación en cuyos derechos se cobra el valor estraido de los bosques. Todo esto está mui bien para el presente, pero nuestros hijos van a encontrar asolado el país, porque nosotros tumbamos el árbol y cegamos la fuente." ${ }^{\text {"35 }}$

Los costos ecológicos de estos procesos no se han medido. No hemos evaluado la dimensión cultural de la colonización, el impacto sobre el medio ambiente ni mucho menos cómo cambió la sociedad frente a esta gran devastación. La lectura que surge de los alegatos de los colonos es su visión épica, el triunfo contra la voracidad del monte y contra todos los recursos disponibles que hacían viable la presencia de especies vegetales y animales. En estos testimonios se pierde la dimensión de la destrucción ecológica que sus esfuerzos conllevaban, para refundir el drama natural que se particulariza en una gesta individual, negándose la historia que subyace en lo épico. Con ello se diluye el sentido fundamental de este proceso social llamado colonización, cual es su poder

33 Diario de Cundinamarca .Bogotá, jueves 21 de enero de 1875, Pág. 261. 
destructivo-constructivo. La liquidación de los microambientes desencadenó el otro drama de Colombia. La cruenta destrucción de cadenas de seres animados e inanimados, necesarios unos y otros, para crear un equilibrio que el hombre vio como hostil. Más que la violencia contra el hombre, el siglo XIX marcó una época de incontenible agresión contra la naturaleza y su medio. ¿Y ésta es la grandeza de la historia de las colonizaciones? Por ello hemos vivido equivocados al suponer que una reflexión en tomo a tales fenómenos debe llevar sólo por los caminos de la nostalgia, el naturalismo y el heroísmo. La novela y la poesía han dejado testimonios de estas visiones. La historia a su vez se ha automutilado al reducir sus análisis a las condiciones de un estado y no a lo que realmente fue la historia de la transformación de un estado a otro. El siglo XIX no es sólo el conocimiento de los procesos políticos y sus güeñas civiles, sino que en las fronteras el conocimiento tiene que ver con el tránsito de un paisaje diseñado por la naturaleza a un paisaje artificial diseñado por el hombre.

Muy pocos comprendieron en el siglo pasado el fenómeno ecológico que continuó intensificándose a lo largo del país. Pero la destrucción de bosques es un capítulo al cual no se ha hecho referencia por la historia y constituye en sí un problema diferente al de los baldíos. En los bosques el problema ecológico está en el corazón del capital, de las exportaciones y de la formación de riquezas. En los baldíos, el problema ecológico es la historia misma de quienes crearon las bases de una propiedad que era necesario legitimar. En conclusión la historia de la colonización, de la explotación de los bosques y de la apropiación de los baldíos tendrá que ser en el futuro la historia de la formación de nuevos ambientes y paisajes. Deberá ser la historia de la economía, de la sociedad y de la cultura. Las experiencias de otras colonizaciones y de otros dramas ambientales ${ }^{34}$ deberán servirnos de estímulo a una reflexión que contribuya a descifrar las claves para comprender por qué hemos creado una cultura para la destrucción y el desorden, para la intolerancia y el odio.

Finalmente, se ha hecho referencia permanente a la región del Caribe colombiano como si fuera una unidad. Es indudable que en ella existen las cicatrices de su entidad fragmentada, diversa y múltiple. Saber qué es lo que hace a todas estas regiones una, pero también diferentes, es la razón de estudio y de su conocimiento. Desentrañar el poder de su nostalgia y la fuerza del caos creador de su goce contribuirá a que otras regiones se comprendan y que de este conocimiento un día podamos explicar, como conesponde a la historia, que la nación somos todos, en una unidad capaz de articular variedades tan propias como el Pacífico, la Orinoquía, los Andes, la Amazonía y el Caribe. Cinco claves de identidad y de verdad que dan a nuestra unidad la esencia de su multiplicidad. Y esa es Colombia, múltiple y dispersa en su unidad diversa.

\footnotetext{
34 George Wolfskill and Stanley Palmer (Edited by) Essays on Frontiers in World History, University of Texas Press, Austin, 1981; Walter Prescott, Webb The Great Plains. A Study in Institutions and Environment, Ginn and Company 1931; Ray A. Billington, America 's Frontier Culture, Texas A\&M University Press, College Station and London, 1977: "The Significance of the Frontier in American History" in The Early Writings of Frederick Jackson Turner, Madison, 1938.
} 